\title{
Historical maps and landscape analysis
}

\author{
Vladimir Kušan ${ }^{\text {a }}$, Stjepan Husnjak ${ }^{\text {b, }}$, Tena Birov ${ }^{\text {a }}$, Ivona Žiža ${ }^{\text {a }}$ \\ a Oikon Ltd. Institute of Applied Ecology, Zagreb, Croatia, Vladimir Kušan, vkusan@oikon.hr, Tena Birov, tbirov@oikon.hr, Ivona \\ Žiža, iziza@oikon.hr \\ ${ }^{b}$ University of Zagreb, Faculty of Agronomy, Zagreb; Croatia, Stjepan Husnjak, shusnjak@agr.hr \\ * Stjepan Husnjak, shusnjak@agr.hr
}

Keywords: Historical maps, Landscape analysis, Georeferencing, Croatia

\begin{abstract}
:
Landscape is a result of natural assets and human work for a long period of time. During that time natural assets are changed by human activities. The most of our surrounding are cultural landscapes as a result of human presence. The main way to study the landscapes is spatial analysis within landscape analysis. Description and investigation of nowadays status of landscapes is not difficult. Understanding the way of landscape development is very difficult because of the lack of data, especially spatial data.
\end{abstract}

Usage of historical maps is the appropriate method of understanding landscape development through past times. For that procedure historical maps should be georeferenced. In this work the examples of georeferencing historical maps from First and Second Military Mapping Survey of Austrian Empire are presented. The usage of georeferenced historical maps was used for the preparation of land use maps for different periods and land use changes analyses. Those changes were used in landscape analyses for the investigation of development of built up areas and hydrological features in the city of Zagreb as well as investigation of authenticity of the areas of the Park of Nature Lonjsko Polje.

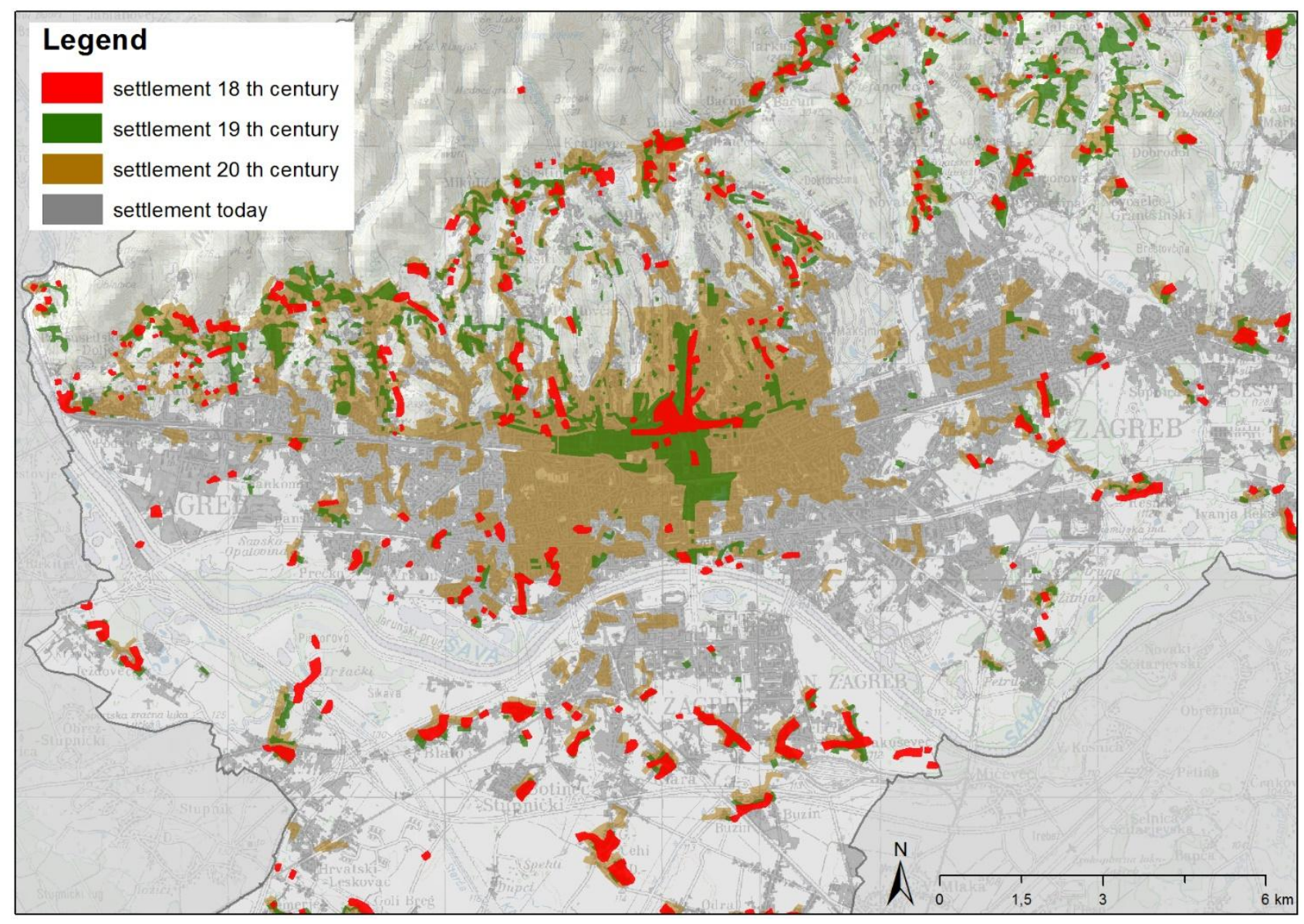

Figure 1. Development of built up areas through centuries - City of Zagreb (central part)

The aim of the project was to prove that the landscape in the area of Lonjsko polje has not changed significantly over the last 250 years. For the area of Lonjsko polje Nature Park, an analysis of landscape authenticity was carried out. As 
there were no methods for evaluating landscape authenticity, we decided to analyze the changes in land use by size and spatial distribution for the last 250 years. For this purpose, we used Austro-Hungarian military maps from 1765. The maps, covering the Nature Park were scanned and georeferenced. Digitalisation of 6 main land use classes (settlements, arable land, forests, seminatural areas, mostly grasslands, marshes and waters) was performed and the land use map in a scale 1:25.000 was produced.

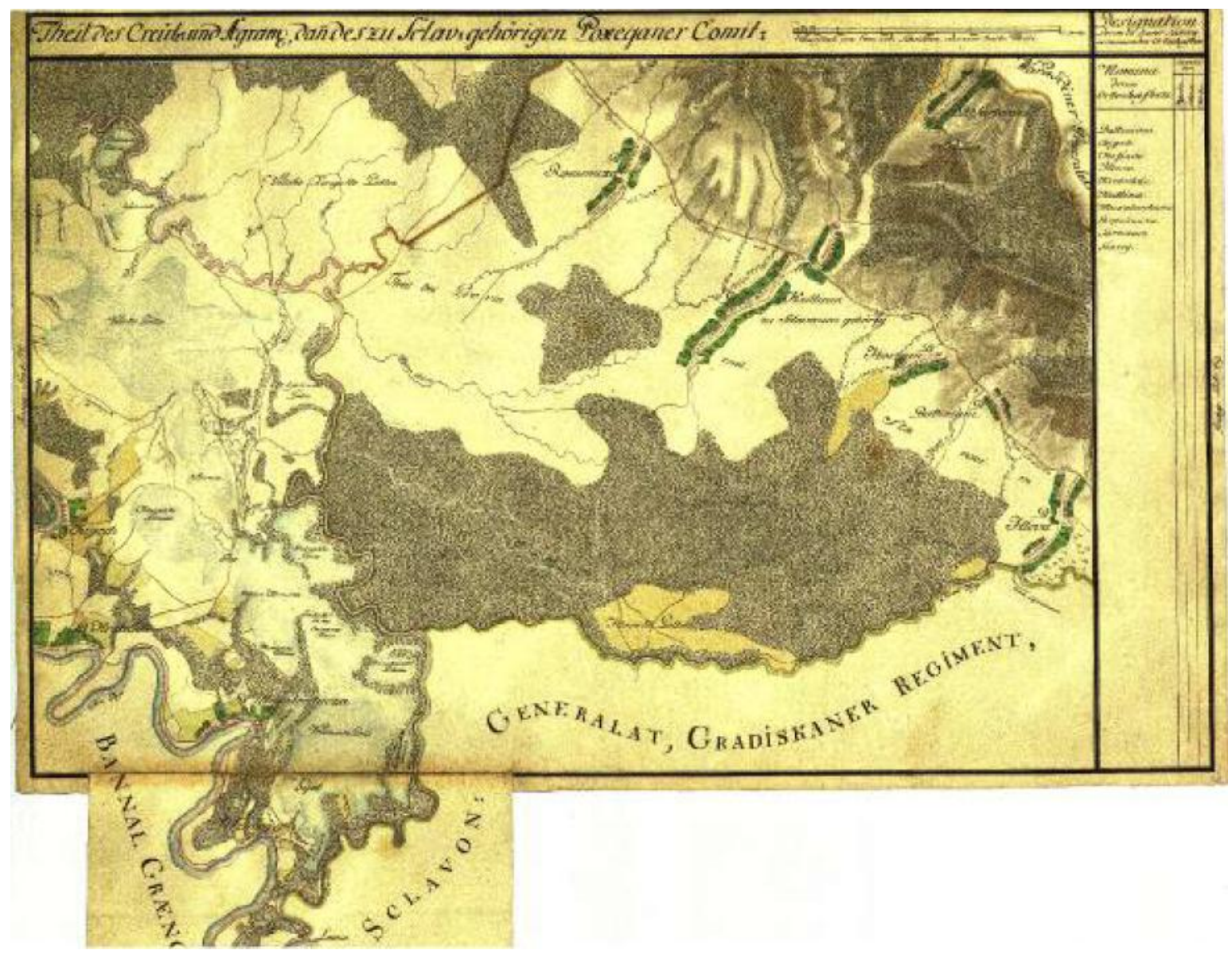

Figure 2. The sheet of Austro-Hungarian military maps from 1765 (original scale 1:28.800)

The land use map for 2005, with accuracy of the map in a scale 1:25.000, was made using CORINE methodology. Orthorectified satellite images (Aster) were vectorised on screen into the same 6 land use classes as the old map. To evaluate the changes between these two maps the union operation was made, and land use flow analysis was performed. The largest surface of the changes occurred in 9 types of changes, with the largest changes being made to the category of grass vegetation that is changed into forests, agricultural land or the swamp. The second largest change was experienced in forests that were changed into agricultural land, grass vegetation or water. The third category that has undergone major changes is the category of swamps that were changed into forests, grass vegetation or agricultural land. Other types of changes took part in the total area with less than $1 \%$ and are not significant any more than the difference in the changes that may have arisen due to cartographic inaccuracies created by georeferencing of the old map.

The land use structure as a landscape element was analyzed on the macro level within squares of $10 \mathrm{~km} \mathrm{x} 10 \mathrm{~km}$ and at a micro level within squares of $2 \mathrm{~km} \times 2 \mathrm{~km}$. Changes in the structure of the land use practice exists but are not significant either on macro level or at the micro level. Thus, changes on macro level are the result of human activities (changes in agricultural areas) and at the micro level changes are more a result of natural processes (succession / regression of vegetation).

Based on the analysis, it can be concluded that changes in land use patterns over the last 250 years exist and are the result of human activities to a small extent or natural processes for the most part. When considering the significance of the changes, it should always have in mind that historical military maps could not be fully integrated into the valid cartographic system. Cartographic inaccuracies created by georeferencing the old map generate changes of small size that should not be considered. 